\title{
UM NOVO ESPÍRITO, SIM! UMA REVISÃO DO DEBATE SOBRE O "ESPÍRITO DO CAPITALISMO"
}

\section{Lúcio Dall Forno ${ }^{1}$}

\section{INTRODUÇÃO}

Segundo Luc Boltanski e Ève Chiapello, no livro "O Novo Espírito do Capitalismo", a história do capitalismo passou por três "espíritos do capitalismo", de acordo com a definição que dão a esse conceito. Sendo que o último espírito ainda está em formação. Isabelle Darmon, baseada na sua interpretação de Max Weber em seu artigo "No 'new spirit'?...", defende que não há um novo espírito, mas sim o mesmo e único.

Para explicar a pertinência da análise de Boltanski e Chiapello para as pesquisas sociais atuais, apesar da crítica de Darmon, inicialmente, será detalhado como os dois primeiros autores definem o conceito de "espírito do capitalismo" e, especialmente, como eles caracterizam os três "espíritos" enumerados por eles. A seguir, será apresentada a explicação de Darmon para a sua defesa de um único "espírito do capitalismo". No próximo tópico, suas críticas serão rebatidas com mais argumentos da obra de Boltanski e Chiapello. Por último, serão feitas as considerações finais visando responder a questão deste artigo: se ainda é válido situarmos o universo empírico de uma pesquisa num contexto de "espírito de capitalismo", conforme a definição de Boltanski e Chiapello.

\section{OS TRÊS ESPÍRITOS}

Mestrando do Programa de Pós-Graduação em Sociologia Política da Universidade Federal de Santa Catarina - UFSC.

Em Tese, Florianópolis, v. 11, n. 1, jan.jjun., 2014. ISSN: 1806-5023 
O livro "O Novo Espírito do Capitalismo" - cujo projeto foi concebido no início de 1995 - nasceu, conforme seus autores, da preocupação provocada pela coexistência entre a degradação da situação econômica e social de um número crescente de pessoas e um capitalismo em plena expansão e profundamente transformado. Essa preocupação foi recrudescida pelo estado da crítica social que nunca havia parecido até então tão desarmada, segundo a percepção dos autores (Boltanski; Chiapello, 2009, p. 19).

Nesse livro, Boltanski e Chiapello identificam o capitalismo como um sistema "absurdo". Os assalariados perderam a propriedade do resultado de seu trabalho e a possibilidade de levar uma vida ativa fora da subordinação. Por outro lado, os capitalistas estão presos a um processo infindável e insaciável, totalmente abstrato e dissociado da satisfação de necessidades de consumo, mesmo que supérfluas (Ibid., p. 38). Afinal, o "capitalismo", conforme a definição dos autores é um sistema caracterizado pela "exigência de acumulação ilimitada do capital por meios formalmente pacíficos" (Ibid., p. 35).

As motivações materiais, por si só, mostram-se bem pouco estimulantes. Os autores citam os psicólogos do trabalho, que têm evidenciado com regularidade que no caso do salário, por exemplo - tal tipo de motivação se constitui no máximo para permanecer num emprego, mas não para um empregado se empenhar. Do mesmo modo, a coerção também é insuficiente, sobretudo quando o empenho exigido pressupõe adesão ativa, iniciativas e sacrifícios livremente assumidos, como aquilo que cada vez mais se espera não só de executivos, mas do conjunto dos assalariados (Ibid., pp. 38-9).

Por isso, a inserção no processo capitalista carece de justificações, pois exige a mobilização de um número imenso de pessoas cujas chances de lucro são pequenas. Os autores definem, então, "espírito do capitalismo" como a ideologia que justifica o engajamento no capitalismo, não só apresentando benefícios individuais, mas também vantagens coletivas definidas como "bem comum" (Ibid., pp. 38-9). Assim, os autores identificaram que a história do capitalismo passou por três "espíritos" que serão descritos resumidamente a seguir (Ibid., pp. 49-52; 57).

O primeiro espírito foi descrito em fins do século XIX, tanto na ficção quanto nas ciências sociais propriamente ditas. Centra-se na figura do "burguês empreendedor", cuja característica se concentra nos elementos heróicos da situação, com a tônica no 


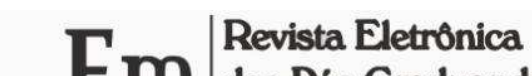

jogo, na especulação, no risco, na inovação (Sombart, 1928, p. 55 apud Boltanski; Chiapello, 2009, p. 49-50).

A aventura capitalista encarna-se na libertação, possibilitada pelo desenvolvimento dos meios de comunicação e do trabalho assalariado, o que permite que os jovens se emancipem das comunidades locais, da ligação à terra, do arraigamento familiar e das formas tradicionais de dependência pessoal.

Em contrapartida, os elementos de segurança se configuram numa combinação entre disposições econômicas inovadoras e posicionamentos domésticos tradicionais. Avareza ou parcimônia, espírito poupador, tendência a racionalizar a vida cotidiana em todos os seus aspectos, desenvolvimento de habilidades contábeis, de cálculo e previsão, aliados com a importância atribuída à família, à linhagem, ao patrimônio, à castidade das moças para evitar casamentos desvantajosos e dilapidação do capital, e o caráter familiar ou patriarcal das relações mantidas com os empregados em firmas pequenas (Braudel, 1979, pp. 526-7 apud Boltanski; Chiapello, 2009, p. 49). Bem como o papel atribuído à caridade para aliviar o sofrimento dos pobres (Procacchi, 1993 apud Boltanski; Chiapello, 2009, p. 50). Esse espírito estava sintonizado com as formas do capitalismo essencialmente familiar de uma época em que o gigantismo ainda não era buscado, salvo em raríssimos casos. Os proprietários e patrões eram conhecidos pessoalmente por seus empregados. O destino e a vida da empresa estavam fortemente associados aos destinos de uma família.

Quanto às justificações de um bem comum, estão menos ligadas à referência ao liberalismo econômico, ao mercado ou à economia acadêmica - cuja difusão ainda era bastante limitada - e mais à crença no progresso, no futuro, na ciência, na técnica, nos benefícios da indústria. Lança-se mão de um utilitarismo vulgar para justificar os sacrifícios exigidos pela marcha do progresso.

É exatamente esse amálgama de disposições e valores diferentes e até incompatíveis, no princípio da divisão dos burgueses consigo mesmos, de que fala François Furet (1995, pp. 19-35 apud Boltanski; Chiapello, 2009, p. 50), que constitui a base daquilo que será denunciado com mais unanimidade e persistência: a hipocrisia.

O segundo espírito tem pleno desenvolvimento entre os anos 30 e 60 . A tônica aí recai menos sobre o empresário individual e mais sobre a organização, centrada no 


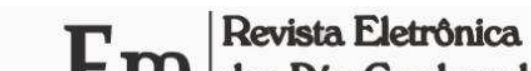

desenvolvimento da grande empresa industrial centralizada e burocratizada no início do século XX. Porém, só algumas empresas (a minoria) podem ser qualificadas como multinacionais. O quadro de acionistas tornou-se mais anônimo, enquanto numerosas empresas se desvincularam do nome e do destino de determinada família.

Tem como figura heróica o "diretor" ou o "dirigente assalariado" que, diferentemente do acionista que procura aumentar sua riqueza pessoal, é habitado pela vontade de aumentar ilimitadamente o tamanho da firma que ele dirige, com o fim de desenvolver uma produção de massa, baseada em economias de escala, na padronização dos produtos, na organização racional do trabalho e em novas técnicas de ampliação dos mercados (marketing).

Com a utilização de um quadro de supervisores cada vez mais qualificados por diploma universitário, as oportunidades oferecidas pelas organizações são muito estimulantes para os jovens diplomados, tanto no sentido de atingir posições de poder a partir das quais se possa mudar o mundo, quanto de obter a libertação de necessidades e a realização de desejos graças à produção e o consumo em massa.

A racionalização e planificação de longo prazo e o gigantismo das organizações constituem ambientes protetores, capazes de oferecer não só perspectivas de carreira, mas também infraestrutura para a vida cotidiana (moradias funcionais, centros recreacionais, organismos formadores) com base no modelo do exército.

Quanto à referência a um bem comum, é feita não só por meio de um ideal de ordem industrial, mas também de um ideal que pode ser qualificado de "cívico", no sentido de enfatizar a solidariedade institucional e a socialização da produção, da distribuição e do consumo, bem como a colaboração entre as grandes empresas e o Estado com o objetivo de alcançar a justiça social.

A multiplicação de proprietários constituídos por pessoas jurídicas - em vez de pessoas físicas - ou os limites impostos à propriedade da empresa - especialmente com o desenvolvimento de direitos dos assalariados e a existência de regras burocráticas que restrinjam as prerrogativas patronais em matéria de gerenciamento do pessoal - são interpretados como um dos indícios do aparecimento de um capitalismo animado por um espírito de justiça social, marcado pela atenuação da luta de classes e dissociação entre propriedade do capital e controle empresarial (Galbraith, 1952, 1968 apud 
Boltanski; Chiapello, 2009, p. 51).

O terceiro espírito se encontra ainda em formação. Assim como as saídas da crise ideológica do primeiro espírito, na segunda metade dos anos 30, não podiam ser previstas; vive-se o mesmo com uma crise do segundo espírito. Hoje, as garantias conferidas pelos diplomas superiores diminuíram, as aposentadorias estão ameaçadas e as carreiras já não são asseguradas. O poder de mobilização do "segundo espírito" é questionado. Ao mesmo tempo que as formas de acumulação se transformaram, de novo, profundamente. O "fim da ilusão comunista" é um fenômeno característico do contexto atual que impõe um desafio para se esboçar uma saída praticável ao capitalismo.

Segundo os autores, o terceiro espírito deverá ser isomorfo a um capitalismo "globalizado" e que põe em prática novas tecnologias, apenas para citar os dois aspectos mais frequentemente mencionados na qualificação do capitalismo de hoje. Eles também sugerem que a formação de um terceiro espírito do capitalismo e sua encarnação em dispositivos dependerão em grande medida do interesse apresentado pelas multinacionais - hoje dominantes - pela manutenção de uma zona pacificada no centro do sistema-mundo, na qual seja possível sustentar um viveiro de executivos, onde eles possam formar-se, criar seus filhos e sentir-se seguros.

\section{UM ÚNICO "ESPÍRITO"}

Contrapondo a ideia de Boltanski e Chiapello, Isabelle Darmon ${ }^{2}$ (2011), em seu artigo "No 'new spirit'? Max Weber's account of the dynamic of contemporary capitalism through 'pure adaptation' and the shaping of adequate subjects", é categórica em dizer que não há um novo espírito, mas sim um único. Sua análise é baseada na sua interpretação do segundo capítulo de "A Ética Protestante e o Espírito do Capitalismo" de Max Weber e nas respostas às suas críticas em "Rebuttals" (mais claramente na segunda resposta a Rachfahl). Portanto, as menções a um capitalismo

2 Minha análise da autora se baseia no seu texto original em inglês, que será exposta, no corpo do meu artigo, em português, conforme minha tradução.

Em Tese, Florianópolis, v. 11, n. 1, jan.jjun., 2014. ISSN: 1806-5023 


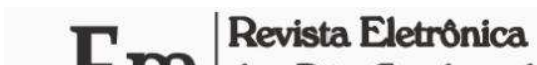

"contemporâneo" ou "avançado" feitas pela autora se referem ao capitalismo da época do autor (Ibid, p. 193).

Baseada em Weber, Darmon define o espírito do capitalismo como o trabalho e o "fazer-dinheiro" enquanto fins absolutos em si mesmos, perseguidos racionalmente e tratados como uma vocação (Weber, 1920, p. 46, 54 apud Darmon, 2011, p. 196). A ideia de um "novo espírito", para ela, é problemática e ilusória, pois alguma renovação só poderia ocorrer dentro dos limites de toda a adaptação à racionalidade do "cosmo da moderna economia capitalista racionalizada" (Weber, 1991, p. 214 apud Darmon, 2011, p. 194). Enquanto a adaptação à "racionalidade formal calculista do capitalismo" prevalecer, haverá o mesmo sistema capitalista e com o mesmo espírito; ou seja, "sem uma nova racionalidade econômica, não há um novo espírito do capitalismo" (Darmon, 2011, p. 213).

A interação entre o racional e o irracional - ou, "em termos mais rigorosos", "entre um tipo de racionalidade e o que, do ponto de vista de tal racionalidade, é irracional" - esteve no núcleo da mobilização de massa para o capitalismo racional moderno. E os resultados desse "conflito ordenado" estão subordinados à racionalidade do mercado. Tal interação é o que sustenta a evolução do capitalismo contemporâneo como uma "esfera diferenciada" de ação humana (Ibid., p. 197; 200; 211). A esfera econômica passa a adquirir uma "lógica própria", com sua própria capacidade para mobilização, sem qualquer necessidade de recorrer à noção de contribuição do capitalismo a um "bem comum": "a peculiaridade da objetivação capitalista não está nem na sua característica ética, nem anti-ética, mas simplesmente não-ética"(Ibid., p. $194-5 ; 211)$.

Entretanto, a impossibilidade de ética na esfera econômica não significa que não surja uma necessidade para os indivíduos de justificar a si mesmos como sujeitos econômicos tomando parte no sistema capitalista, especialmente em frente aos "protestos" contra o "espírito do capitalismo". Porém, a tal justificação falta todos os traços daquela "unidade consistente da auto-justificação ética" que caracteriza os primeiros capitalistas protestantes (Ibid., p. 210-1).

Se antes a mobilização para esse "espírito" se dava através de uma educação e de uma constante avaliação ética, interna e externa, hoje ela é um produto de pura 


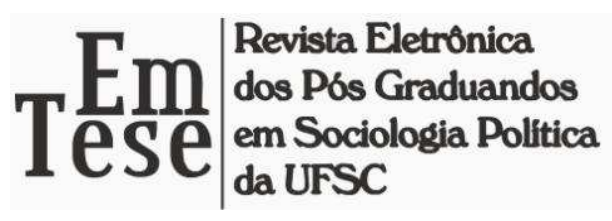

"adaptação" às condições do capitalismo avançado (Weber, 1920, p. 55; 2002, p. 32 apud Darmon, 2011, p. 197). Ou seja, longe de contarmos com um "novo espírito", o capitalismo avançado simplesmente se desenvolve promovendo "pura adaptação" e "sujeitos econômicos" tanto adequados quanto ativos (Darmon, 2011, p. 1; 194).

Weber, segundo Darmon, questiona radicalmente o status da justificação, numa esfera sustentada pela adaptação, como correspondente à legitimação da participação de alguns na economia capitalista e como discursos facilmente reconhecidos como substitutos da ética uma vez defendida (Weber, 1910, p. 574; 2001, p. 102 apud Darmon, 2011, p. 211). Ele complementa dizendo que são os interesses subjacentes às políticas comerciais e sociais que tendem a determinar as concepções do mundo e não o inverso (Idem, 1920, p. 56 apud Darmon, 2011, p. 211).

Dessa forma, revela-se o "caráter extremamente artificial" de uma suposta "mobilização" numa economia capitalista, na qual um indivíduo nasce e que é dada a ele, ao menos enquanto um indivíduo, como um invólucro inalterável no qual ele deve viver. Sendo assim, faria mais sentido falar na construção de uma disposição (Eingestelltheit) ou de um habitus, ao invés de um esforço de mobilização, escolha ou convencimento em um engajamento (Darmon, 2011, p. 196; 201; 209). Essa disposição, além de assegurar a adaptação dos indivíduos às demandas de um sistema, também cria renovadas tensões entre as racionalidades formal e material ou, conforme mencionado anteriormente em outros termos, entre o racional e o irracional (Darmon, 2011, p. 211).

Conforme a interpretação de Carlos Eduardo Sell, não encontramos propriamente definições prévias do que seja a racionalidade formal e a material nos escritos weberianos. Porém, esse autor identifica, no segundo capítulo de "Economia e Sociedade”, pela primeira vez, uma distinção entre duas formas de racionalidade econômica. Resumidamente, a primeira se refere à aplicação rigorosa da lógica fria do cálculo de custo e benefício, enquanto que a segunda permite introduzir uma avaliação valorativa - ética, política ou outras quaisquer - das conseqüências sociais da atividade econômica (Weber, 1994, p. 52 apud Sell, 2012, p. 163).

\section{UM "BEM COMUM" É REALMENTE NECESSÁRIO?}


Além da diferença principal entre as duas teses expostas - se há ou não um "novo espírito" -, há a diferença na definição do conceito de "espírito do capitalismo". Darmon cita como Weber o definiu: como “o trabalho e o 'fazer-dinheiro' enquanto fins absolutos em si mesmos, perseguidos racionalmente e tratados como uma vocação". Boltanski e Chiapello o apresentam como "a ideologia que justifica o engajamento no capitalismo, não só apresentando benefícios individuais, mas também vantagens coletivas definidas como 'bem comum'".

Esses dois últimos autores também reconhecem, como característica do capitalismo, a acumulação do capital como um fim em si (Boltanski; Chiapello, 2009, p. 53). Porém, uma divergência importante está na inclusão da referência a um "bem comum" nesse espírito. Eles deixam essa diferença mais clara quando dizem que Weber insiste na necessidade de o capitalismo apresentar razões individuais, ao passo que Albert Hirschman lança luz sobre as justificações em termos de um bem comum. Boltanski e Chiapello alegam retomar essas duas dimensões, inserindo o termo justificação numa acepção que possibilite abarcar ao mesmo tempo as justificações individuais (aquilo em que uma pessoa encontra motivos para empenhar-se na empresa capitalista) e as justificações gerais (em que sentido o empenho na empresa capitalista serve ao bem comum) (Boltanski; Chiapello, 2009, p. 39-41).

Resumindo e comparando a explicação de Weber e Hirschman: no primeiro, o “espírito do capitalismo" remete ao conjunto dos motivos éticos que, embora estranhos em sua finalidade à lógica capitalista, inspiram os empresários em suas ações favoráveis à acumulação do capital. Segundo ele, foi com a Reforma Protestante que se impôs a crença de que o dever é cumprido, em primeiro lugar, pelo exercício de um ofício nas atividades temporais, em oposição à vida religiosa fora do mundo, privilegiada pelo ethos católico. A concepção do trabalho como vocação religiosa servia de ponto de apoio normativo para os comerciantes e os empreendedores do capitalismo nascente, dando-lhes boa "motivação psicológica", como diz Weber, para se entregar à racionalização implacável de seus negócios e à busca de um lucro máximo (1964, p. 108 apud Boltanski; Chiapello, 2009, p. 40). Ela também lhes servia porque os operários 


\section{Tese}

compenetrados da mesma ideia mostravam-se dóceis, incansáveis e convencidos de que o homem deve cumprir seu dever onde quer que a providência o tenha colocado.

Hirschman (1980 apud Boltanski; Chiapello, 2009, p. 40-1), em vez de recorrer a móveis psicológicos e a busca da salvação pessoal, menciona motivos que teriam, em primeiro lugar, afetado a esfera política antes de tocar a economia. As atividades lucrativas teriam sido valorizadas pelas elites, no século XVIII, devido às vantagens sociopolíticas que delas eram esperadas. Na sua interpretação, o pensamento laico do Iluminismo justifica as atividades lucrativas como um bem comum para a sociedade. Em vista da incapacidade da moral religiosa para coibir as paixões humanas, da impotência da razão para governar os homens e da dificuldade de submeter as paixões por meio da pura repressão, restava a solução que consistia em utilizar uma paixão para compensar as outras. Assim, o lucro, que até então encabeçava a ordem das desordens, obteve o privilégio de ser eleito a paixão inofensiva sobre a qual passou a recair o encargo de subjugar as paixões ofensivas.

Para Darmon, a referência a um "bem comum” é desnecessária para o capitalismo, pois, com o seu desenvolvimento, a esfera econômica passou a funcionar sob uma "lógica própria", com sua própria capacidade de mobilização e seu caráter "não-ético", promovendo os sujeitos adequados a esse sistema econômico e a "pura adaptação" a ele, com a construção de disposições (Eingestellheit) ou habitus.

Para Boltanski e Chiapello, a noção de "prova" contribui para rebater essa tese (Boltanski; Chiapello, 2009, p. 59; 65-67). A justificação do capitalismo, diante das numerosas críticas de que é objeto, deve se submeter a "provas de realidade". As provas são sempre provas "de força", como uma queda de braço ou o confronto entre um pescador e uma truta, ou seja, a revelação dos poderes se traduz pela determinação de certo grau de força. Mas, quando a situação estiver sujeita a injunções justificativas e os protagonistas julgarem que essas injunções são realmente respeitadas, uma prova passa a ser considerada "legítima", ou seja, cujos poderes é revelado por um juízo sobre a grandeza respectiva das pessoas. Enquanto a atribuição de uma força define um estado de coisas sem nenhum colorido moral, a atribuição de uma grandeza supõe um juízo referente não só à força respectiva dos seres em questão, mas também ao caráter justo da ordem revelada pela prova. Garantir a justiça de uma prova é formalizá-la e verificar 
sua execução, para prevenir que ela seja parasitada por forças exteriores.

Segundo os autores, a noção de prova rompe com uma concepção estritamente determinista do social, quer esta se baseie na onipotência das estruturas, quer na “dominação de normas interiorizadas". Essa noção enfatiza a incerteza presente em graus diversos nas situações da vida social na perspectiva da ação. Ela possibilita o deslocamento entre o micro e o macro no sentido de orientar tanto para dispositivos setoriais ou situações singulares quanto para organizações sociais, pois as grandes tendências de seleção social repousam, em última análise, na natureza das provas que uma sociedade reconhece em determinado momento. Logo, o impacto da crítica sobre o capitalismo ocorre por meio dos seus efeitos sobre as provas, pois coloca em xeque a ordem existente, fazendo a suspeita recair sobre o estado de grandeza dos seres em questão e desvendando as injustiças suscitadas pela ação das forças ocultas.

Apesar das duas teses reconhecerem o caráter "não-ético" ou "amoral" do capitalismo, Boltanski e Chiapello defendem a necessidade de uma referência a um "bem comum" exatamente devido a essa característica, pois a questão da justiça não é pertinente no âmbito em que a acumulação do capital atua, "salvo se a crítica o obrigar a justificar-se e a fiscalizar-se". Portanto, a exigência de justificação está ligada à possibilidade de crítica (Boltanski; Chiapello, 2009, p. 56; 71).

Outra semelhança entre Darmon e os outros dois autores é a referência à influência da interação entre as racionalidades formal e material no desenvolvimento do capitalismo. Ela mesma reconhece, em sua crítica, a semelhança dessa interação com a apresentada por Boltanski e Chiapello entre a "justificação" e a "crítica" (Darmon, 2011, p. 211). Porém, para esses últimos, a indiferença normativa do capitalismo faz com que ele precise de seus "inimigos" para encontrar os pontos de apoio morais que lhe faltam para incorporar dispositivos de justiça. Ele deve obter recursos fora de si mesmo, nas crenças que, em determinado momento, têm importante poder de persuasão, inclusive nas que lhe são hostis. A justificação do capitalismo, portanto, supõe referência a construtos de outra ordem, da qual derivam exigências completamente diferentes daquelas impostas pela busca do lucro (Boltanski; Chiapello, 2009, p. 53; $61)$.

Pode-se comparar o processo pelo qual se incorporam ao capitalismo ideias que 


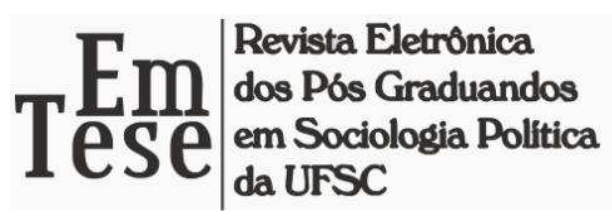

lhe eram inicialmente estranhas, e até hostis, ao processo de aculturação descrito por Dumont (1991 apud Boltanski; Chiapello, 2009, p. 53-4) quando este mostra como a ideologia moderna do individualismo se difunde forjando composições com as culturas preexistentes. Do encontro e do conflito dos dois conjuntos de ideias-valores nascem representações novas que são uma espécie de síntese. Um efeito notável dessa aculturação é que "não só as representações individualistas não se diluem nem se desvanecem nas combinações em que entram, mas, ao contrário, extraem nessas associações com seus contrários uma adaptabilidade superior e uma força aumentada".

Porém, há situações em que a referência ao "bem comum” não é percebida como necessária, como quando parece ser difícil responder à crítica, cujas investidas obrigam a tensionar incessantemente a prova e a aumentar seu custo. Em vez disso, busca-se novos caminhos para os lucros, realizando-se "deslocamentos", que podem ser geográficos, como na transferência para regiões em que a mão-de-obra seja barata e o direito do trabalho seja pouco desenvolvido ou pouco respeitado. As mesmas observações podem ser feitas em relação às exigências sobre o meio ambiente (Boltanski; Chiapello, 2009, p. 69).

Mas, nem todos os deslocamentos devem ser relacionados com a crítica, que se traduz no endurecimento e na insistência das provas, bem como na baixa dos lucros, sem modificação do restante. A própria dinâmica do capitalismo está apenas parcialmente ligada a esse tipo de crítica, denominada "crítica Voice", na conceituação de Hischmann (1972 apud Boltanski; Chiapello, 2009, p. 78-9).

Conviria, então, acrescentar a "crítica Exit" (também de acordo com Hirschman), ou seja, a crítica da concorrência (Boltanski; Chiapello, 2009, p. 78-9). Tal crítica é a recusa da compra por parte do consumidor ou do cliente em sentido amplo, recusa de ser contratado por parte do assalariado potencial, ou recusa de serviço por parte do prestador autônomo etc. É uma crítica à qual o capitalismo aceita com mais facilidade se submeter, embora ele também procure, nesse caso, escapar aos entraves que ela provoca - por exemplo, constituindo monopólios ou cartéis - de tal maneira que acaba ignorando os intuitos de deserção, que então deixam de ter como se exprimir. A rivalidade que a concorrência mantém entre os capitalistas os obriga a buscar incessantemente vantagens sobre seus concorrentes, por meio da inovação tecnológica, 


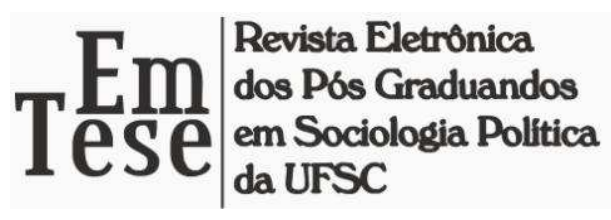

da busca de novos produtos ou serviços, da melhora dos já existentes e da modificação dos modos de organização do trabalho, de tal modo que encontramos aí uma das causas de mudança perpétua do capitalismo, segundo o processo de "destruição criativa", descrito por Schumpeter (1963 apud Boltanski; Chiapello, 2009, p. 79).

A mudança dos dispositivos de acumulação capitalista tem o efeito de desarmar temporariamente a crítica, mas também tem grandes probabilidades de a médio prazo conduzir à reformulação de um novo espírito do capitalismo a fim de restabelecer o envolvimento dos assalariados que, nesse movimento, perderam os referenciais aos quais se apegavam para terem controle sobre seu trabalho (Boltanski; Chiapello, 2009, p. 64). Mesmo quando as forças críticas parecem em total decomposição, a capacidade de indignar-se pode permanecer intacta. Ela está presente sobretudo nos jovens, que não passaram ainda pela experiência do fechamento do campo das possibilidades, constitutiva do envelhecimento, podendo formar o substrato a partir do qual seja possível o restabelecimento da crítica. Aí reside a garantia de um trabalho crítico sempre renovado (Boltanski; Chiapello, 2009, p. 72).

\section{CONSIDERAÇÕES FINAIS}

Então, quantos "espíritos" temos, afinal? Para responder a essa pergunta, precisa-se primeiramente definir de que "espírito do capitalismo" estamos falando, pois esse conceito possui duas definições diferentes: a que foi dada por Weber, conforme a exposição de Darmon, e a que foi dada na obra de Boltanski e Chiapello. Talvez, se os dois últimos autores tivessem se referido a tal ideologia de engajamento de outra forma, entrariam menos em atrito com uma preocupação purista com o pensamento de Weber. Porém, a crítica de Darmon não era apenas sobre o desvirtuamento de um conceito, mas com uma ideia específica na sua reformulação: a do capitalismo necessitar de se justificar através de uma noção de "bem comum". Para ela, a simples adaptação e produção de sujeitos adequados já garantiriam uma mobilização.

Assim como Boltanski e Chiapello, Darmon também reconhece a necessidade

Em Tese, Florianópolis, v. 11, n. 1, jan./jun., 2014. ISSN: 1806-5023 


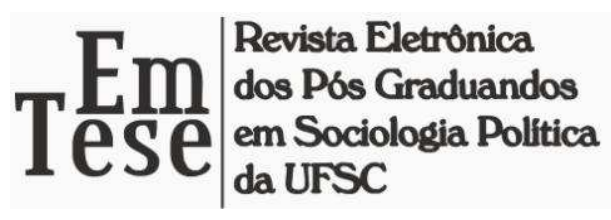

dos indivíduos de justificar a si mesmos como sujeitos participantes no sistema capitalista. Porém, ela não explica que "traços daquela unidade consistente da autojustificação ética" dos "primeiros capitalistas protestantes" faltam a tais justificações. O máximo que ela faz é citar Weber ao questionar radicalmente o status da justificação numa esfera sustentada pela adaptação, servindo para a legitimação da participação de alguns na economia capitalista e como substitutos da ética uma vez defendida. Ela lembra, ainda, que ele diz que são os interesses subjacentes às políticas comerciais e sociais que tendem a determinar as concepções do mundo, e não o inverso. Onde entraria a influência da "crítica" sobre tais políticas? Dever-se-ia pensar numa relação dialética nesse caso, pois não há motivos para não considerar a elaboração de uma crítica como uma concepção de mundo.

Por outro lado, considerando que um indivíduo nasce numa economia capitalista que lhe é dada como "um invólucro inalterável no qual ele deve viver", a ideia de uma "adaptação" parece bastante convincente. Mas, falar de apenas "um único espírito" pode levar a uma interpretação de que essa produção de "sujeitos adequados" ocorre de uma mesma forma, sem alterações.

Darmon se apoia no fato do capitalismo ter atuado sob uma "mesma racionalidade econômica" - "moderna", "formal", "calculista" - para defender que não há um "novo espírito". Entretanto, essa constância serviria para defender a permanência de um mesmo "espírito"? Se essa racionalidade for uma característica inerente ao capitalismo, não serviria. Pois, uma mudança nessa racionalidade poderia implicar não apenas numa mudança "no" sistema, mas numa mudança "de" sistema, isto é, o fim do capitalismo. Ademais, os três "espíritos" enumerados por Boltanski e Chiapello são "do capitalismo", de uma mesma coisa, de um mesmo sistema econômico que, até então, funciona sob uma racionalidade específica, conforme identifica Darmon. Por isso, não há contradição em falar em mudança de "espírito" sem mudança de racionalidade.

No entanto, a própria Darmon pode nos dar uma pista sobre a que mudanças Boltanski e Chiapello estão de fato se referindo, quando ela diz que alguma renovação só poderia ocorrer dentro dos limites de toda a adaptação a tal racionalidade, ou que a disposição (Eingestelltheit) contribui para criar renovadas tensões entre as racionalidades formal e material. 
Se considerarmos as renovações na tensão entre tais racionalidades como a mudança que acontece na ideologia para a mobilização no capitalismo, então podemos considerar a pertinência em situar um determinado contexto como fazendo parte de um dos três "espíritos" enumerados por Boltanski e Chiapello (e quem sabe de outros mais que estarão por vir). Em suma, poderíamos considerar as mudanças no "espírito do capitalismo" como uma mudança na relação entre as racionalidades formal e material, ou entre o "racional" e o "irracional" ou, ainda, entre crítica e justificação; ao invés de pensarmos como uma mudança na "racionalidade econômica".

Outra questão importante levantada nesse confronto de ideias é a do "caráter extremamente artificial" da mobilização. Ele traz de volta um velho debate na Sociologia entre determinismo versus liberdade, ou sobre a relação entre estrutura e agência. Trata-se de uma relação muito complexa que dificilmente encerrará essa discussão tão cedo, na minha opinião. A contribuição de Boltanski e Chiapello para essa questão, conforme foi mencionado anteriormente, está na noção de "prova" como uma possibilidade de romper com uma concepção estritamente determinista do social, enfatizando a incerteza presente em graus diversos nas situações da vida social e orientando uma análise tanto para dispositivos setoriais ou situações singulares quanto para organizações sociais. Num texto mais recente, criticando as explicações deterministas, Boltanski (2001, p. 15) questiona: por que tanto esforço para criticar e justificar se, em última análise, forças inconscientes fazem esse trabalho? Para responder a essa pergunta, ele se propõe a colocar a crítica no centro das suas indagações, considerando-a uma prática corrente das pessoas ditas "vulgares". Dessa forma, o autor visa substituir uma "sociologia crítica" por uma "sociologia da crítica".

\section{REFERÊNCIAS}

BOLTANSKI, Luc. A moral da rede? Críticas e justificações nas evoluções recentes do capitalismo. In: Fórum Sociológico. Instituto de Estudos e Divulgação Sociológica, Número 5/6, II $^{\mathrm{a}} \quad$ Série, 2001, pp.13-35. Disponível em: <http://forumsociologico.fcsh.unl.pt/PDF/Artigo1.pdf>. Acesso em: 27 nov. 2014 


\section{Tese}

BOLTANSKI, Luc; CHIAPELLO, Ève. O novo espírito do capitalismo. São Paulo: Martins Fontes, 2009.

BRAUDEL, F. Civilisation matérielle, économie et capitalisme, XV-XVII siècle, 3 vol. (1. Les structures du quotidien, 2. Les jeux de I'échange, 3. Le temps du monde), Paris: Annand Colin. [Trad. bras., Civilização material, economia e capitalismo, vol. 3, São Paulo: Martins Fontes, 1996], 1979.

DARMON, Isabelle. No 'new spirit'? Max Weber's account of the dynamic of contemporary capitalism through 'pure adaptation' and the shaping of adequate subjects. Max Weber Studies, Vol. 11, Issue 2, p 193-216, 24p, Jul 2011.

DUMONT, L. L' IdéoIogie Allemande: France-AIlemagne et retour, Homo-AequaIis II. Paris: Callimard, 1991.

FURET, F. Le Passé d'Une Illusion: essai sur l'idée communiste au xx' siècle. Paris: Robert Laffont-Calmann -Lévy, 1995.

CALBRAITH, J. K. American Capitalism: the Concept of Contervailing Power. Boston: Houghton Mifflin, 1952.

GALBRAITH, J. K. Le Nouvel État Industriel: essai sur le capitalisme américain. Paris: Gallimard (1ª edição americana: 1967), 1968.

HIRSCHMAN, A, Exit, Voice and Loyaulty. Cambridge (Mass.): Harvard University Press (traduction de C. Eeysseyrias: Face au déclin des entreprises et des institutions, Paris, Les Editions ouvrieres, 1972), 1970.

HIRSCHMAN, A. Les Passions et Les Intérêts. Paris: PUF, 1980.

PROCACCHI, G. Gouverner la Misére: la question sociale en France, 1789-1848. Paris: Seuil, 1993.

SCHUMPETER, J. Capitalisme, Socialisme et Démocratie. Paris: Payot, 1963.

SELL, Carlos Eduardo. Racionalidade e racionalização em Max Weber. Rev. Bras. Ci. Soc., São Paulo, v. 27, n. 79, June 2012. Disponível em: <http://www.scielo.br/pdf/rbcsoc/v27n79/a10.pdf>. Acesso em: 28 mar. 2014. 


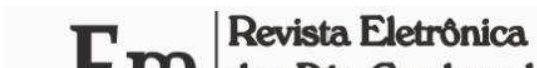

SOMBART, W. Le Bourgeois. Paris: Payot (traduction de S. Jankélévitch, $1^{\text {a }}$ edição alemã: 1913; 1ª edição francesa: 1928), 1966.

WEBER, M. Antikritisches Schlußwort zum "Geist des Kapitalismus". Archiv für Sozialwissenschaft und Sozialpolitik, n. 31, pp. 554-99, 1910.

Die protestantische Ethik und der Geist des Kapitalismus. In: Gesammelte Aufsätze zur Religionssoziologie (ed. Marianne Weber; Tübingen: J.C.B. Mohr [Paul Siebeck]), pp. 17-206, 1920.

Die Wirtschaftsethik der Weltreligionen Konfuzianismus und Taoismus: Schriften 1915-1920, Vol. I/19, Studienausgabe der Max Weber Gesamtausgabe (ed. Helwig Schmidt-Glintzer and Petra Kolonko; Tübingen J.C.B. Mohr [Paul Siebeck]), 1991.

. Economia e sociedade: fundamentos da sociologia compreensiva. 3. ed. Brasília: Editora da UnB, vol. 1, 1994.

1964.

L'Éthique Protestante et l'Esprit du Capitalisme. Paris: Pion, (1ª edição: 1920),

The Protestant Ethic and The Spirit of Capitalism. Ed. Stephen Kalberg;

Oxford and Los Angeles: Blackwell and Roxbury Publishing Company, 2002. 


\section{RESUMO}

Para Luc Boltanski e Ève Chiapello, a história do capitalismo passou por três "espíritos do capitalismo", de acordo com a definição que dão ao conceito. Sendo que, o último espírito ainda está em formação. Isabelle Darmon, baseada na sua interpretação de Max Weber, defende que não há um novo espírito, mas sim o mesmo e único, pois "sem uma nova racionalidade econômica, não há um novo espírito do capitalismo”. Este artigo visa fazer uma revisão do debate entre os autores e responder a seguinte pergunta: diante da crítica de Darmon, é válido ainda situarmos o universo empírico de uma pesquisa num contexto de "espírito de capitalismo", conforme a definição de Boltanski e Chiapello? Concluo que sim, se considerarmos as mudanças em tal "espírito" como renovações na interação entre as racionalidades formal e material.

PALAVRAS-CHAVE: Capitalismo. Espírito do capitalismo. Max Weber.

\section{ABSTRACT}

For Luc Boltanski and Ève Chiapello, the history of capitalism has gone through three "spirits of capitalism", according to the definition given by them to the concept. The last spirit is still in formation. Based on her interpretation of Max Weber, Isabelle Darmon defends that there isn't a new spirit, but the only and the same one, because "without a new economic rationality, there is not a new spirit of capitalism". This article aims to review the debate between the authors and to answer the following question: facing Darmon's critique, is it valid even situate an empirical universe of research in a context of "spirit of capitalism", as the definition of Boltanski and Chiapello? I conclude that it is, if we consider the changes in such "spirit" as renovations in the interplay between formal and material rationalities. 


\section{C.mista Eletrónica

KEY-WORDS: Capitalism. Spirit of capitalism. Max Weber.

Recebido em: 24 de abril de 2014

Aceito para publicação em: 27 de maio de 2014 